\title{
Effects of Chung-Pae Inhalation Therapy on a Mouse Model of Chronic Obstructive Pulmonary Disease
}

\author{
Joon-Ho Hwang, ${ }^{1}$ Beom-Joon Lee, ${ }^{1}$ Hee Jae Jung, ${ }^{1}$ Kwan-Il Kim, ${ }^{1}$ Jun-Yong Choi, \\ Myungsoo Joo, ${ }^{2}$ and Sung-Ki Jung ${ }^{1}$ \\ ${ }^{1}$ Division of Allergy, Immune and Respiratory System, Department of Internal Medicine, College of Korean Medicine, \\ Kyung Hee University, Seoul 130-701, Republic of Korea \\ ${ }^{2}$ School of Korean Medicine, Pusan National University, Yangsan 626-870, Republic of Korea \\ Correspondence should be addressed to Myungsoo Joo; mjoo@pusan.ac.kr and Sung-Ki Jung; jskes1@gmail.com
}

Received 25 June 2015; Accepted 13 August 2015

Academic Editor: Ken Yasukawa

Copyright (C) 2015 Joon-Ho Hwang et al. This is an open access article distributed under the Creative Commons Attribution License, which permits unrestricted use, distribution, and reproduction in any medium, provided the original work is properly cited.

\begin{abstract}
Chung-pae (CP) inhalation therapy is a method frequently used in Korea to treat lung disease, especially chronic obstructive pulmonary disease (COPD). This study investigated the effects of CP inhalation on a COPD animal model. C57BL/6 mice received porcine pancreatic elastase (PPE) and lipopolysaccharide (LPS) alternately three times for 3 weeks to induce COPD. Then, CP (5 or $20 \mathrm{mg} / \mathrm{kg}$ ) was administered every $2 \mathrm{~h}$ after the final LPS administration. The effect of CP was evaluated by bronchoalveolar lavage (BAL) fluid analysis, histological analysis of lung tissue, and reverse transcription polymerase chain reaction analysis of mRNA of interleukin- (IL-) $1 \beta$, tumor necrosis factor- (TNF-) $\alpha$, IL-6, and tumor growth factor- (TGF-) $\beta$. Intratracheal CP administration reduced the number of leukocytes and neutrophils in BAL fluid, inhibited the histological appearance of lung damage, and decreased the mRNA levels of the proinflammatory cytokines IL- $1 \beta$, TNF- $\alpha$, IL- 6 , and TGF- $\beta$. Intratracheal CP administration effectively decreased the chronic inflammation and pathological changes in a PPE- and LPS-induced COPD mouse model. Therefore, we suggest that $\mathrm{CP}$ is a promising strategy for COPD.
\end{abstract}

\section{Introduction}

Inhalation therapy is a treatment technique for administering a variety of inhalable drugs to target lung tissue, airway secretion components, and microorganisms in the upper, central, and/or peripheral airways [1]. Such therapy is used widely to treat chronic obstructive pulmonary disease (COPD) in the respiratory tract [2]. Inhalation administration has an advantage over oral administration for treating respiratory disease in that it allows rapid and substantial drug absorption and has fewer side effects [3]. Typically, herbal medicines are administered orally in the form of decoction or granular extract; however, several studies have reported the direct delivery of herbal medicine to the airway via inhalation [4-7]. The current study employed the MicroSprayer, which generates a plume of liquid aerosol (mass median diameter (MMD) of $16-22 \mu \mathrm{m}$ ), enabling the administration of drugs directly to the lung via the trachea [8].
Chung-pae (CP), composed of Ephedrae Herba, Caryophylli Flos, Pogostemonis (Agastachis) Herba, and Zingiberis Rhizoma Crudus, is a representative aerosol agent used in the respiratory clinic at Kyung Hee Oriental Medicine Hospital, Seoul, Korea, for relieving the symptoms of patients with dyspnea and cough. Previously, we investigated the effect of intratracheal (i.t.) CP administration on lipopolysaccharide(LPS-) induced acute lung injury (ALI) in a mouse model. We found that CP suppressed neutrophil infiltration to the lung and reduced the production of proinflammatory cytokines via decreased expression of the proinflammatory transcription factor, nuclear factor kappa-light-chain-enhancer of activated $\mathrm{B}$ cells $(\mathrm{NF}-\kappa \mathrm{B})$, and activation of the antiinflammatory factor, nuclear factor erythroid 2 (NF-E2)related factor 2 (Nrf2) [7].

The current study investigated the activities of $\mathrm{CP}$ on chronic lung injuries including COPD. COPD was selected for the study because it is a prevalent chronic respiratory 
disease that has become a major public health problem [9]. LPS and porcine pancreatic elastase (PPE) were used to induce COPD in a mouse model. Long-term administration of LPS by inhalation induces emphysema [10-12], and PPE augments the emphysematous changes that are critical characteristics of COPD $[13,14]$.

In the present study, the effect of $\mathrm{CP}$ on chronic lung injury was evaluated in a mouse model of COPD generated using LPS and PPE. The effect of CP was assessed by analyzing bronchoalveolar lavage (BAL) fluid, lung histology, and mRNA levels of proinflammatory cytokines.

\section{Materials and Methods}

2.1. Preparation of Chung-Pae Water Extract (CP). CP was prepared as described previously [7]. Briefly, $20.0 \mathrm{~g}$ Ephedrae, 20.0 g Ephedrae Herba, (Agastachis) Herba, 10.0 g Caryophylli Flos, and $10.0 \mathrm{~g}$ Zingiberis Rhizoma Crudus were boiled in $1 \mathrm{~L}$ distilled water for $2 \mathrm{~h}$. The mixture was concentrated to $50 \mathrm{~mL}$ with a low-pressure evaporator and then freeze-dried to yield $6.0 \mathrm{~g}$ of powder.

2.2. Animals. Male C57BL/6 mice were supplied by Orient Bio Inc. (Seongnam, Korea) and were bred in a pathogen-free facility at Pusan National University, Yangsan, Korea. Animals were housed in certified standard laboratory cages and fed with food and water ad libitum prior to the experiments. All experimental procedures were approved by the Guidelines of the Institutional Animal Care and Use Committee of Pusan National University, Busan, Republic of Korea (protocol number: PNU-2010-00028).

2.3. COPD Mouse Model and Treatment. COPD was induced in mice using the method reported previously with some modifications [15]. A MicroSprayer (syringe assembly, MSA250-m, the Penn Century Inc., PA, USA) was used to deliver all materials to the lungs via i.t. Mice (20-30 g) were exposed to $0.25 \mathrm{U}$ of PPE (on days 1, 7, and 14) and $7.0 \mu \mathrm{g}$ of LPS (on days 4,11 , and 18) for three consecutive weeks. In this manner, the treated mice received PPE and LPS alternately. Two doses of CP (low dose of $5 \mathrm{mg} / \mathrm{kg}$ and high dose of $20 \mathrm{mg} / \mathrm{kg}$ ) in $25 \mu \mathrm{L}$ of PBS were administered $2 \mathrm{~h}$ after every LPS administration. The vehicle-treated group was treated with $25 \mu \mathrm{L}$ of PBS using the same method and treatment schedule as the CP-treated group. Normal, untreated non-COPD mice were included as a control in the analyses.

2.4. BAL Fluid Analysis. BAL fluid analysis was conducted on day 21. BAL was obtained using two consecutive instillations of PBS $(1.0 \mathrm{~mL})$ using a 24-gauge intravascular catheter. The total cell number was determined using a hemocytometer. Macrophages, lymphocytes, and neutrophils were counted by Hemacolor (Merck, Darmstadt, Germany) after centrifugation and staining; 100 cells were counted for each microscopic field, and the mean number of cells per field was reported.

2.5. Lung Histological Analysis. Mice were perfused with saline and the whole lung was inflated with fixatives. After paraffin embedding, lung tissue were cut in $5-\mu \mathrm{m}$ thick slices and stained with hematoxylin and eosin (H\&E). Three separate $H \& E$-stained sections were evaluated in each mouse under a microscope using 100x magnification.

2.6. Isolation of Total RNA from Tissue and Reverse-Transcription-Polymerase Chain Reaction (RT-PCR). Total RNA was isolated with the QIAGEN RNeasy mini kit (Qiagen, Hilden, Germany) according to the manufacturer's instructions. Two micrograms of total RNA were reverse-transcribed by M-MLV reverse transcriptase (Promega, Madison, WI, USA), and single-stranded cDNA was amplified by PCR using specific primers. The forward and the reverse primers for interleukin- (IL-) $1 \beta$ were $5^{\prime}$-TCATGGGATGATGATGATAACCTGCT- $3^{\prime}$ and $5^{\prime}$-CCCATACTTTAGGAAGACACGGATT- $3^{\prime}$, respectively; the primers for tumor necrosis factor- (TNF-) $\alpha$ were $5^{\prime}$-GGCAGGTCTACTTTGGAGTCATTGC- $3^{\prime}$ and $5^{\prime}$-ACATTCGAGGCTCCAGTGAATTCGG- $3^{\prime}$, respectively; the primers for IL- 6 were $5^{\prime}-\mathrm{CTG}$ GTGACAACCACGGCCTTCCCTA-3' and $5^{\prime}$-ATGCTTAGGCATAACGCACTAGGTT-3', respectively; the primers for tumor growth factor- (TGF-) $\beta$ were $5^{\prime}$-GCGGCAGCTGTACATTGACT- $3^{\prime}$ and $5^{\prime}$-ACTGTGTGTCCAGGCTCCAA- $3^{\prime}$, respectively; and the primers for glyceraldehyde3-phosphate dehydrogenase (GAPDH) were $5^{\prime}$-GGAGCCAAAAGGGTCATCAT- $3^{\prime}$ and $5^{\prime}$-GTGATGGCATGGACTGTGGT-3', respectively. For PCR amplification, TaqPCRx DNA polymerase recombinant (Invitrogen, Carlsbad, CA, USA) was used according to the manufacturer's protocol. The reaction conditions were as follows: initial denaturation at $95^{\circ} \mathrm{C}$ for $5 \mathrm{~min}$ followed by $22-30$ cycles of denaturation for $40 \mathrm{sec}$ at $95^{\circ} \mathrm{C}$, annealing for $40 \mathrm{sec}$ at $57^{\circ} \mathrm{C}$, and extension for $50 \mathrm{sec}$ at $72^{\circ} \mathrm{C}$ with a final extension for $7 \mathrm{~min}$ at $72^{\circ} \mathrm{C}$. Amplicons were separated in $1.2 \%$ agarose gels in boric acid buffer at $100 \mathrm{~V}$ for $30 \mathrm{~min}$, stained with ethidium bromide, and visualized under UV light. GAPDH was used as an internal control to evaluate the relative expressions of IL- $1 \beta$, TNF- $\alpha$, IL-6, and TGF- $\beta$.

2.7. Statistical Analysis. Group comparisons were performed using one-way analysis of variance (ANOVA) with Duncan's post hoc test. The analysis was conducted using SPSS 18.0 for Windows (SPSS, Chicago, IL, USA). $p$ values $<0.05$ were considered to indicate significant differences. All experiments were performed independently at least three times.

\section{Results}

3.1. Effect of CP on the Total Cell Count and Inflammatory Cell Numbers in the BAL Fluid of PPE- and LPS-Induced COPD Mice. The total cell and neutrophil counts in the BAL fluid of PPE- and LPS-induced COPD mice increased significantly compared to those in the normal group $(p<0.01$, Figures 1(a) and 1(b)). CP treatment significantly decreased the total cell and neutrophil counts in the BAL fluid compared to the vehicle-treated group ( $p<0.05$, Figures $1(\mathrm{a})$ and $1(\mathrm{~b})$ ). However, no difference was detected between groups treated with 5 or $20 \mathrm{mg} / \mathrm{kg} \mathrm{CP}$.

The macrophage population in the vehicle-treated group increased significantly compared to that in the normal group 


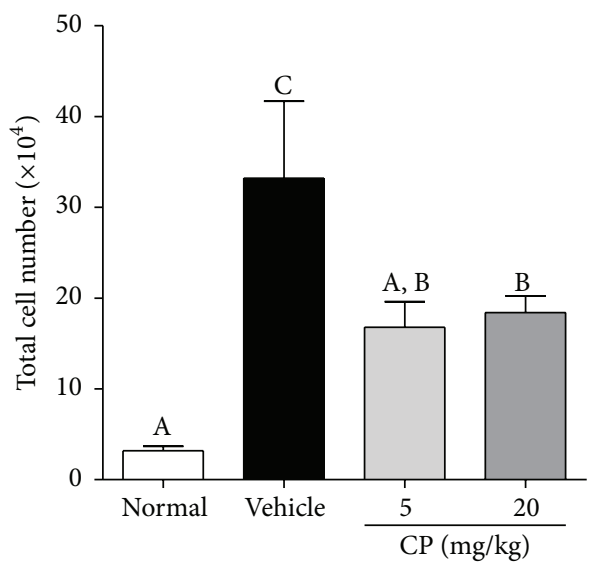

(a)

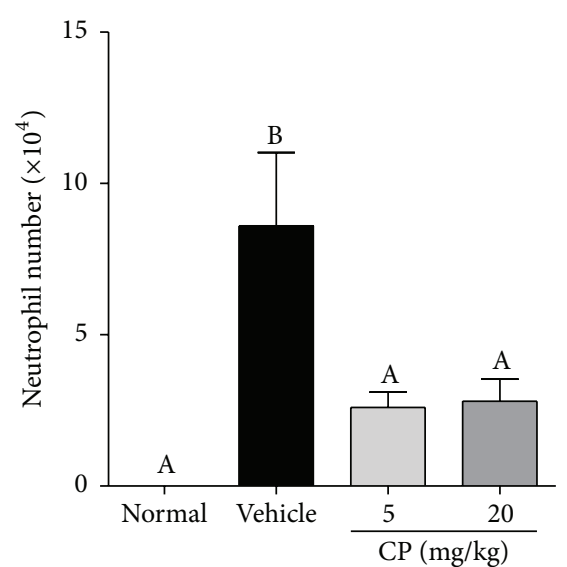

(b)

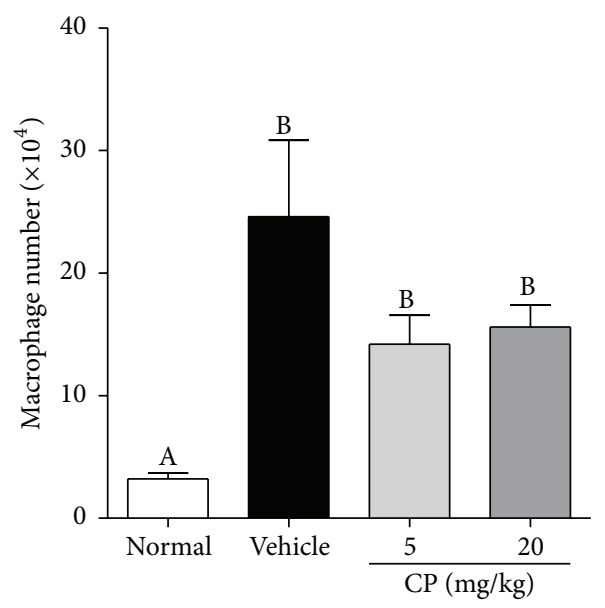

(c)

Figure 1: Effect of CP on the total cell number (a), number of neutrophils (b), and number of macrophages (c) in the BAL fluid of PPEand LPS-induced COPD mice. Data are presented as means \pm SEM $(n=5)$. Letters $(A-C)$ indicate different levels of significance (95\% level, Duncan's test).

$(p<0.01$, Figure $1(c))$. However, CP did not decrease the macrophage population in the BAL fluid compared to the vehicle-treated group.

\subsection{Effect of CP on the Histological Evidence of Lung Dam-} age in PPE- and LPS-Induced COPD Mice. Larger vacuoles were present in the lung sections of vehicle-treated mice (Figure 2(b)) compared with the normal group (Figure 2(a)). Such enlarged air spaces suggested alveolar destruction due to emphysematous change. However, CP-treated COPD mice showed smaller vacuoles (Figures $2(\mathrm{c})$ and $2(\mathrm{~d})$ ) compared to the vehicle-treated group, suggesting that CP (5 or $20 \mathrm{mg} / \mathrm{kg}$ ) ameliorated inflammation in the lung.

3.3. Effect of CP on the $m R N A$ Expression Levels of Cytokines in the PPE- and LPS-Induced COPD Mice. CP (5 or $20 \mathrm{mg} / \mathrm{kg}$ ) decreased the mRNA levels of IL- $1 \beta$, TNF- $\alpha$, and IL- 6 in the lung (Figure 3), which was in agreement with the decreased numbers of inflammatory cells in the BAL fluid. However, a significant decrease in TGF- $\beta$ expression was observed only in mice treated with $20 \mathrm{mg} / \mathrm{kg}$ CP.

\section{Discussion}

In the current study, i.t. administration of CP to PPE- and LPS-induced COPD mice reduced the number of leukocytes and neutrophils in the BAL fluid, inhibited lung injury, and decreased the mRNA levels of the proinflammatory cytokines IL-1 $\beta$, TNF- $\alpha$, IL- 6 , and TGF- $\beta$.

In our clinic, patients usually received $\mathrm{CP}$ at a daily dose of $5 \mathrm{mg} / \mathrm{kg}$; however, long-term administration of $20 \mathrm{mg} / \mathrm{kg}$ of CP for 3 weeks showed no adverse effect on vital organs, including the liver and kidney (data not shown). Therefore, in this study, we administered CP at doses of 5 or $20 \mathrm{mg} / \mathrm{kg}$ in the PPE- and LPS-induced COPD mice. Infiltration of inflammatory cells in the BAL fluid was observed in the PPEand LPS-induced COPD mice. Subsequent i.t. administration of CP reduced the total number of infiltrating cells, especially neutrophils, suggesting that CP could inhibit neutrophils, the most deleterious inflammatory mediator in COPD. However, CP did not significantly decrease the macrophage number compared to the vehicle-treated group (42.3\% versus $37.6 \%$ ); this result was consistent with a previous study [7]. 


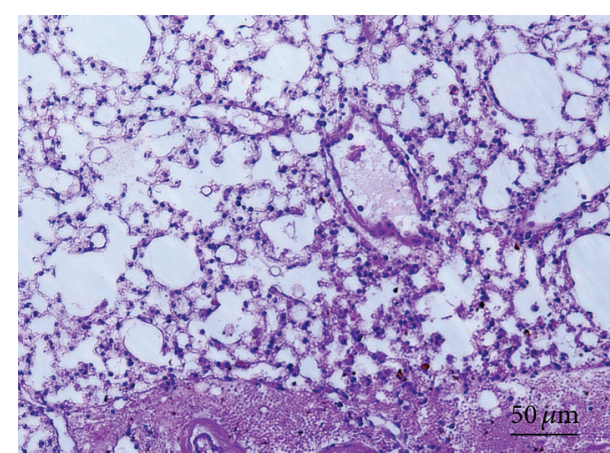

(a)

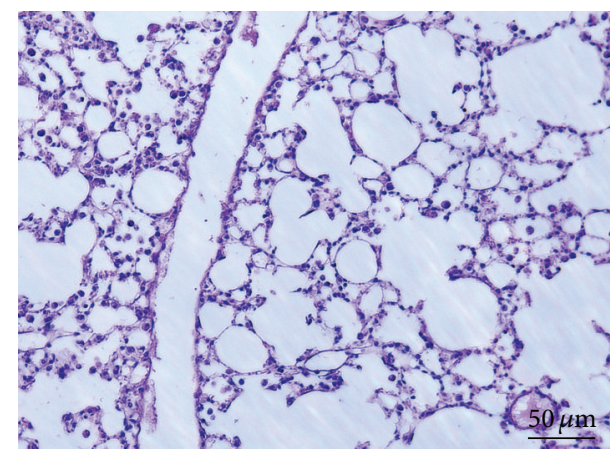

(c)

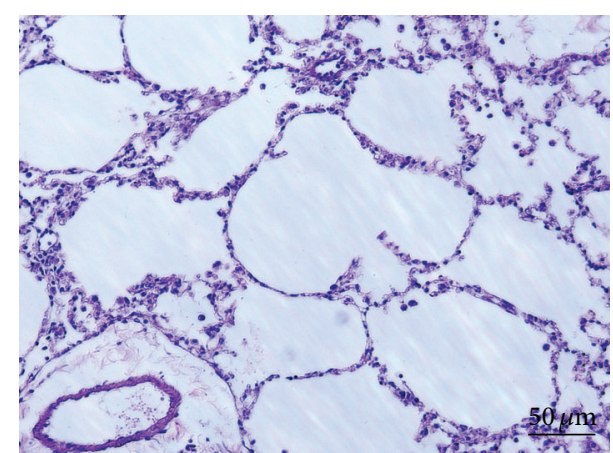

(b)

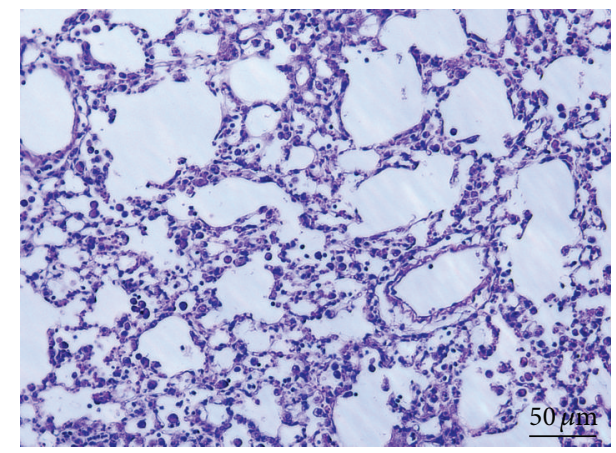

(d)

FIGURE 2: Effect of CP on the histological evidence of lung damage in the PPE- and LPS-induced COPD mice: (a) normal group; (b) vehicletreated group; (c) CP-treated group (5 mg/kg); and (d) CP-treated group (20 mg/kg).

COPD is characterized mainly by increased levels of activated neutrophils, macrophages, and T-lymphocytes [16]. Macrophages mediate inflammation in COPD through the release of chemokines that attract neutrophils, monocytes, and T-cells [17]. Neutrophils are key mediators of COPD, as they migrate to the airway under the control of chemotactic factors and become activated $[18,19]$. Activated neutrophils secrete proteolytic enzymes that can induce emphysema as well as numerous lung-damaging, proinflammatory cytokines and chemokines (e.g., matrix metalloproteinase(MMP-) 8, 9, and 12) [20-22]. Moreover, increased numbers of neutrophils in the airway lumen and BAL fluid in individuals with COPD are correlated with disease severity [23, 24].

The COPD model used in this study involved the inhalation of LPS and elastase to induce emphysematous change $[14,25]$. Generally, emphysema is induced by a proteolyticantiproteolytic imbalance. Proteolytic enzymes may augment the inflammatory cell influx into airspaces, which causes destruction of alveolar septa and increased airspaces [10, 26]. Thus, air space enlargement is a criterion used for measuring the severity of emphysematous change $[10,27,28]$. In the current study, CP reduced the vacuole size compared to that in the vehicle group, suggesting that it prevented alveolar destruction. Histological analysis of lung tissue showed increased cell and neutrophil numbers in the BAL fluid.

Numerous cytokines play important roles in the pathological processes of COPD through the recruitment, activation, and survival of inflammatory cells. TNF- $\alpha$ and IL$1 \beta$ have long been known to be classical proinflammatory cytokines that contribute to the development of COPD [2931]. IL- 6 is stimulated by TNF- $\alpha$ and IL- $1 \beta$ and also plays a critical role in the pathogenesis of emphysematous change [32]. These proinflammatory cytokines influence one another and amplify the inflammatory response in COPD $[16,33]$. TGF- $\beta$, a profibrotic cytokine, is one of the main mediators involved in tissue remodeling in the lungs and contributes to architectural changes in the lungs in COPD [34-37]. The blocking of TGF- $\beta$ improves emphysematous changes $[38,39]$, although a low concentration of activated TGF- $\beta$ is required to maintain alveolar homeostasis and prevent the development of emphysema [40,41]. Therefore, inhibition of proinflammatory cytokines is one of the most promising treatments for COPD [42]. In this study, CP reduced the mRNA levels of these cytokines in the lung, suggesting the suppression of chronic inflammation and pathological changes as well as the associated neutrophil infiltration in the lung.

\section{Conclusion}

Previously, we have demonstrated the therapeutic effect of i.t. CP administration on ALI [7]. The current study provides experimental evidence that long-term administration of $\mathrm{CP}$ has a therapeutic effect on chronic lung injury in a COPD mouse model induced by PPE and LPS. The antiinflammatory effect exerted by i.t. CP administration suggests that it could be a new therapeutic formula and that inhalation 


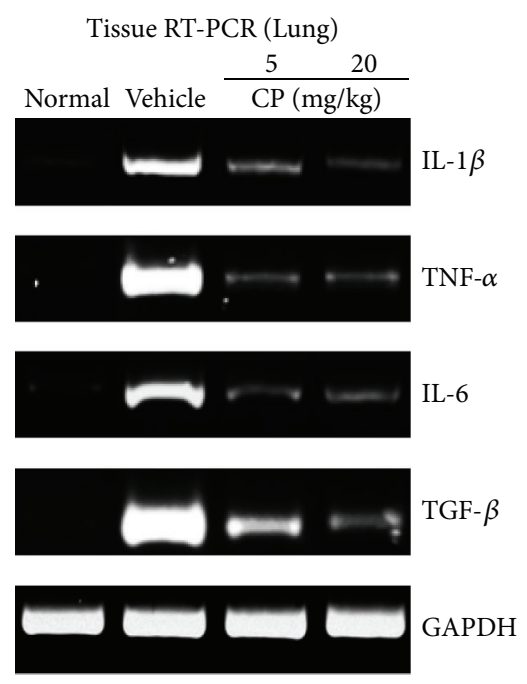

(a)

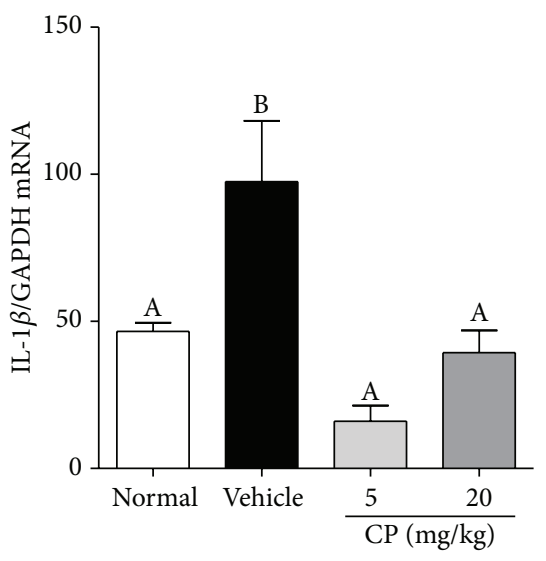

(b)

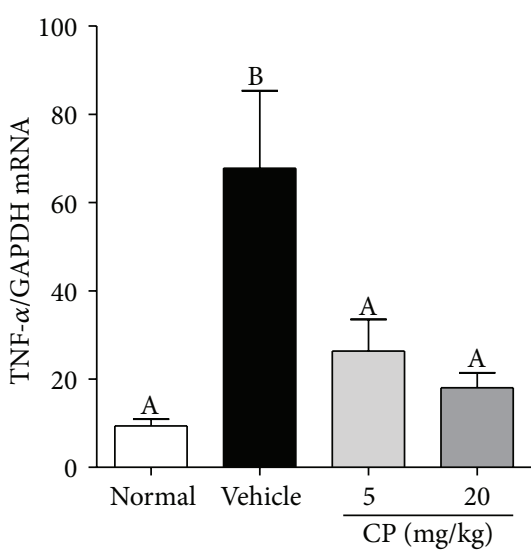

(c)

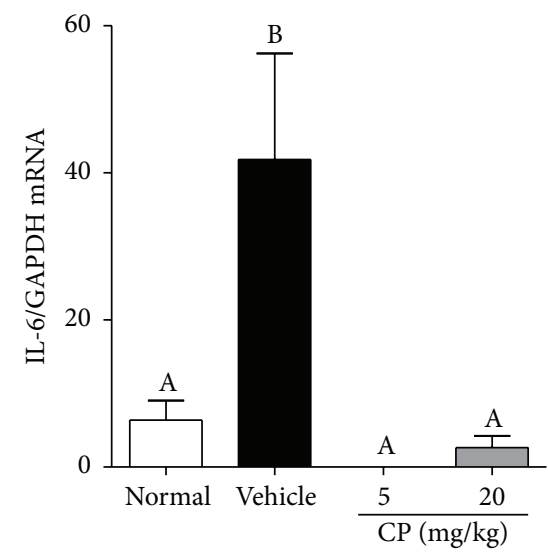

(d)

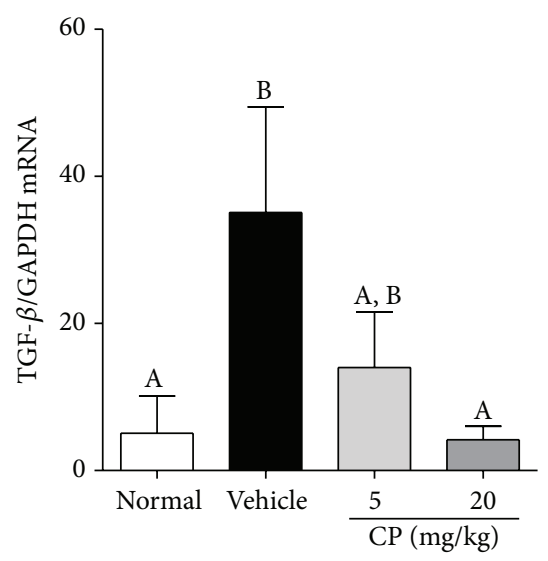

(e)

FIGURE 3: Effect of CP on the mRNA levels of cytokines in the lung of PPE- and LPS-induced COPD mice. Mice were exposed to PPE (on days 1,7 , and 14) and LPS (on days 4, 11, and 18) and administered $5 \mathrm{mg} / \mathrm{kg}$ or $20 \mathrm{mg} / \mathrm{kg}$ of CP $2 \mathrm{~h}$ after every LPS administration. The lungs of variously treated mice were harvested on day 21 for RT-PCR analysis. The intensity of each PCR band was measured by densitometric analysis (a), and relative expression of each gene was calculated over GAPDH. CP reduced the mRNA level of these cytokines (b-e). Data are presented as means \pm SEM $(n=5)$. Letters $(A-C)$ indicate different levels of significance ( $95 \%$ level; Duncan's test).

of herbal medicine can be a promising strategy for treatment of COPD.

\section{Conflict of Interests}

The authors declare that there is no conflict of interests regarding the publication of this paper.

\section{Authors' Contribution}

Myungsoo Joo and Sung-Ki Jung designed research and contributed to the editing of the paper. Joon-Ho Hwang and Beom-Joon Lee contributed equally as first authors. All authors read and approved the final paper.

\section{Acknowledgment}

This work was supported by a Grant to Korean Medical Science Research Center for Healthy Aging from the National Research Foundation of Korean Government (2014R1A5A2009936).

\section{References}

[1] L. Lannefors, "Inhalation therapy: practical considerations for nebulisation therapy," Physical Therapy Reviews, vol.11, no. 1, pp. 21-27, 2006.

[2] H.-K. Chan, "Inhalation drug delivery devices and emerging technologies," Expert Opinion on Therapeutic Patents, vol.13, no. 9, pp. 1333-1343, 2003.

[3] P. R. Byron and J. S. Patton, "Drug delivery via the respiratory tract," Journal of Aerosol Medicine, vol. 7, no. 1, pp. 49-75, 1994.

[4] Y. Lu, "Effection of inhaled SHL to treatment influenza," Modern Journal of Integrated Traditional Chinese and Western Medicine, vol. 18, p. 2523, 2007.

[5] J.-J. Yang, C.-Y. Liu, L.-H. Quan, and Y.-H. Liao, "Preparation and in vitro aerosol performance of spray-dried Shuang-Huang-Lian corrugated particles in carrier-based dry 
powder inhalers," AAPS PharmSciTech, vol. 13, no. 3, pp. 816825, 2012.

[6] Y.-C. Park, M. Jin, S.-H. Kim, M.-H. Kim, U. Namgung, and Y. Yeo, "Effects of inhalable microparticle of flower of Lonicera japonica in a mouse model of COPD," Journal of Ethnopharmacology, vol. 151, no. 1, pp. 123-130, 2014.

[7] K. H. Kim, D.-H. Kim, N. Jeong et al., "Therapeutic effect of Chung-Pae, an experimental herbal formula, on acute lung inflammation is associated with suppression of NF- $\kappa \mathrm{B}$ and activation of Nrf2," Evidence-Based Complementary and Alternative Medicine, vol. 2013, Article ID 659459, 11 pages, 2013.

[8] F. Gagnadoux, A. L. Pape, E. Lemarié et al., "Aerosol delivery of chemotherapy in an orthotopic model of lung cancer," The European Respiratory Journal, vol. 26, no. 4, pp. 657-661, 2005.

[9] A. A. Cruz, J. Bousquet, and N. Khaltaev, Global Surveillance, Prevention and Control of Chronic Respiratory Diseases: A Comprehensive Approach, World Health Organization, 2007.

[10] D. M. Brass, J. W. Hollingsworth, M. Cinque et al., "Chronic LPS inhalation causes emphysema-like changes in mouse lung that are associated with apoptosis," American Journal of Respiratory Cell and Molecular Biology, vol. 39, no. 5, pp. 584-590, 2008.

[11] Y. Kaneko, K. Takashima, N. Suzuki, and K. Yamana, "Effects of theophylline on chronic inflammatory lung injury induced by LPS exposure in guinea pigs," Allergology International, vol. 56, no. 4, pp. 445-456, 2007.

[12] J. H. J. Vernooy, M. A. Dentener, R. J. van Suylen, W. A. Buurman, and E. F. M. Wouters, "Long-term intratracheal lipopolysaccharide exposure in mice results in chronic lung inflammation and persistent pathology," American Journal of Respiratory Cell and Molecular Biology, vol. 26, no. 1, pp. 152-159, 2002.

[13] U. Sajjan, S. Ganesan, A. T. Comstock et al., "Elastase- and LPS-exposed mice display altered responses to rhinovirus infection," The American Journal of Physiology-Lung Cellular and Molecular Physiology, vol. 297, no. 5, pp. L931-L944, 2009.

[14] H. Lee, Y. Kim, H. J. Kim et al., "Herbal formula, PM014, attenuates lung inflammation in a murine model of chronic obstructive pulmonary disease," Evidence-Based Complementary and Alternative Medicine, vol. 2012, Article ID 769830, 10 pages, 2012.

[15] U. Sajjan, S. Ganesan, A. T. Comstock et al., "Elastase- and LPSexposed mice display altered responses to rhinovirus infection," American Journal of Physiology-Lung Cellular and Molecular Physiology, vol. 297, no. 5, pp. L931-L944, 2009.

[16] W. MacNee, "Pathogenesis of chronic obstructive pulmonary disease," Clinics in Chest Medicine, vol. 28, no. 3, pp. 479-513, 2007.

[17] P. J. Barnes, "Alveolar macrophages in chronic obstructive pulmonary disease (COPD)," Cellular and Molecular Biology, vol. 50, pp. OL627-OL637, 2004.

[18] K. Larsson, "Aspects on pathophysiological mechanisms in COPD," Journal of Internal Medicine, vol. 262, no. 3, pp. 311-340, 2007.

[19] M. Meijer, G. T. Rijkers, and F. J. Van Overveld, "Neutrophils and emerging targets for treatment in chronic obstructive pulmonary disease," Expert Review of Clinical Immunology, vol. 9, no. 11, pp. 1055-1068, 2013.

[20] P. J. Barnes, S. D. Shapiro, and R. A. Pauwels, "Chronic obstructive pulmonary disease: molecular and cellularmechanisms," European Respiratory Journal, vol. 22, no. 4, pp. 672-688, 2003.

[21] D. Singh, L. Edwards, R. Tal-Singer, and S. Rennard, "Sputum neutrophils as a biomarker in COPD: findings from the ECLIPSE study," Respiratory Research, vol. 11, article 77, 2010.
[22] G. G. Brusselle, G. F. Joos, and K. R. Bracke, "New insights into the immunology of chronic obstructive pulmonary disease," The Lancet, vol. 378, no. 9795, pp. 1015-1026, 2011.

[23] D. Stănescu, A. Sanna, C. Veriter et al., "Airways obstruction, chronic expectoration, and rapid decline of FEV1 in smokers are associated with increased levels of sputum neutrophils," Thorax, vol. 51, no. 3, pp. 267-271, 1996.

[24] G. Caramori, A. Pandit, and A. Papi, "Is there a difference between chronic airway inflammation in chronic severe asthma and chronic obstructive pulmonary disease?" Current Opinion in Allergy and Clinical Immunology, vol. 5, no. 1, pp. 77-83, 2005.

[25] S. Ganesan, A. N. Faris, A. T. Comstock, J. Sonstein, J. L. Curtis, and U. S. Sajjan, "Elastase/LPS-exposed mice exhibit impaired innate immune responses to bacterial challenge: role of scavenger receptor A," The American Journal of Pathology, vol. 180, no. 1, pp. 61-72, 2012.

[26] J. C. Hogg, "Pathophysiology of airflow limitation in chronic obstructive pulmonary disease," The Lancet, vol. 364, no. 9435, pp. 709-721, 2004.

[27] S. Čužić, M. Bosnar, M. D. Kramarić et al., "Claudin-3 and Clara cell $10 \mathrm{kDa}$ protein as early signals of cigarette smoke-induced epithelial injury along alveolar ducts," Toxicologic Pathology, vol. 40, no. 8, pp. 1169-1187, 2012.

[28] Y.-C. Nie, H. Wu, P.-B. Li et al., "Anti-inflammatory effects of naringin in chronic pulmonary neutrophilic inflammation in cigarette smoke-exposed rats," Journal of Medicinal Food, vol. 15, no. 10, pp. 894-900, 2012.

[29] C. A. Dinarello, "Proinflammatory cytokines," Chest, vol. 118, no. 2, pp. 503-508, 2000.

[30] A. Churg, S. Zhou, X. Wang, R. Wang, and J. L. Wright, "The role of lnterleukin-1 $\beta$ in murine cigarette smoke-induced emphysema and small airway remodeling," The American Journal of Respiratory Cell and Molecular Biology, vol. 40, no. 4, pp. 482490, 2009.

[31] N. S. Pauwels, K. R. Bracke, L. L. Dupont et al., "Role of IL- $1 \alpha$ and the Nlrp3/caspase-1/IL-1 $\beta$ axis in cigarette smoke-induced pulmonary inflammation and COPD," European Respiratory Journal, vol. 38, no. 5, pp. 1019-1028, 2011.

[32] M. Rincon and C. G. Irvin, "Role of IL-6 in asthma and other inflammatory pulmonary diseases," International Journal of Biological Sciences, vol. 8, no. 9, pp. 1281-1290, 2012.

[33] P. J. Barnes, "The cytokine network in chronic obstructive pulmonary disease," American Journal of Respiratory Cell and Molecular Biology, vol. 41, no. 6, pp. 631-638, 2009.

[34] W. I. de Boer, A. van Schadewijk, J. K. Sont et al., “Transforming growth factor $\beta 1$ and recruitment of macrophages and mast cells in airways in chronic obstructive pulmonary disease," American Journal of Respiratory and Critical Care Medicine, vol. 158, no. 6, pp. 1951-1957, 1998.

[35] H. Takizawa, M. Tanaka, K. Takami et al., "Increased expression of transforming growth factor- $\beta 1$ in small airway epithelium from tobacco smokers and patients with chronic obstructive pulmonary disease (COPD)," American Journal of Respiratory and Critical Care Medicine, vol. 163, no. 6, pp. 1476-1483, 2001.

[36] A. Soltani, S. S. Sohal, D. Reid, S. Weston, R. Wood-Baker, and E. H. Walters, "Vessel-associated transforming growth factorbetal (TGF- $\beta 1$ ) is increased in the bronchial reticular basement membrane in COPD and normal smokers," PLoS ONE, vol. 7, no. 6, Article ID e39736, 2012.

[37] S. P. Atamas, S. P. Chapoval, and A. D. Keegan, "Cytokines in chronic respiratory diseases," F1000 Biology Reports, vol. 5, article 3, 2013. 
[38] C. Harrison, "Lung disease: blocking TGF $\beta$ improves emphysema," Nature Reviews Drug Discovery, vol. 11, no. 2, pp. 108-108, 2012.

[39] J. C. Celedón, C. Lange, B. A. Raby et al., "The transforming growth factor- $\beta 1$ (TGFB1) gene is associated with chronic obstructive pulmonary disease (COPD)," Human Molecular Genetics, vol. 13, no. 15, pp. 1649-1656, 2004.

[40] D. Sheppard, "Transforming growth factor $\beta$ : a central modulator of pulmonary and airway inflammation and fibrosis," Proceedings of the American Thoracic Society, vol. 3, no. 5, pp. 413-417, 2006.

[41] D. G. Morris, X. Huang, N. Kaminski et al., "Loss of integrin [alpha]v[beta]6-mediated TGF-[beta] activation causes Mmp12-dependent emphysema," Nature, vol. 422, no. 6928, pp. 169-173, 2003.

[42] G. Caramori, I. M. Adcock, A. Di Stefano, and K. F. Chung, "Cytokine inhibition in the treatment of COPD," International Journal of Chronic Obstructive Pulmonary Disease, vol. 9, pp. 397-412, 2014. 


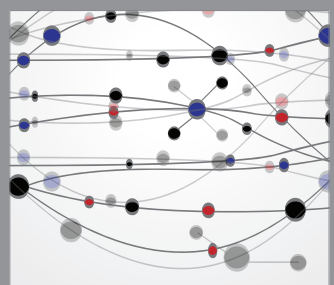

The Scientific World Journal
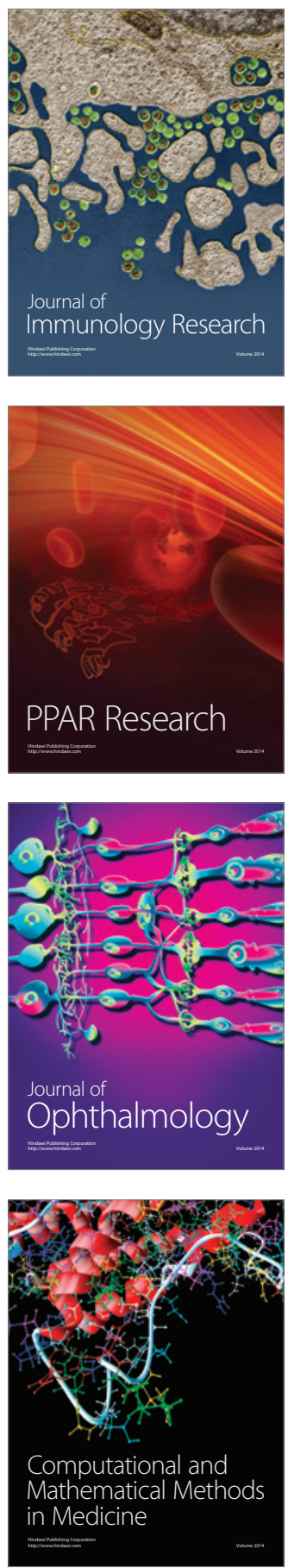

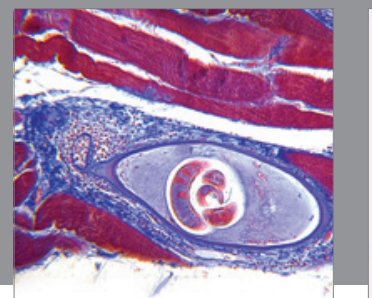

Gastroenterology

Research and Practice
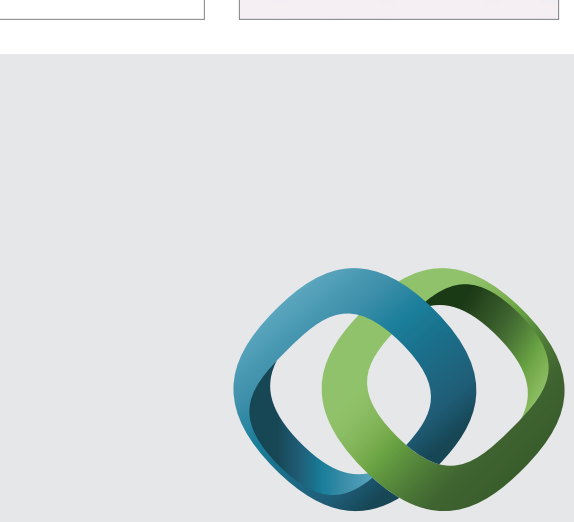

\section{Hindawi}

Submit your manuscripts at

http://www.hindawi.com
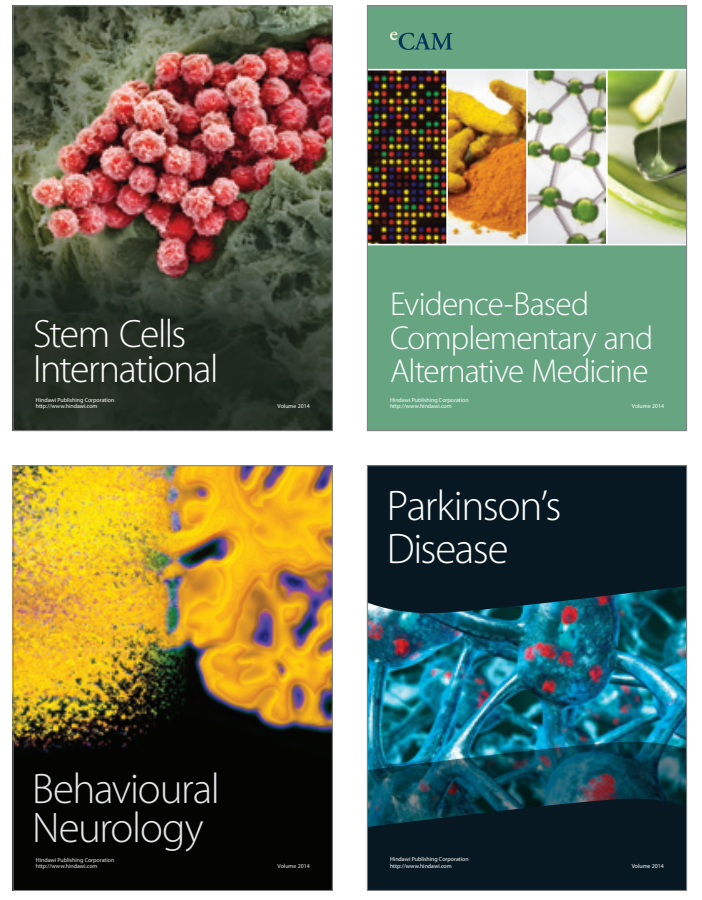
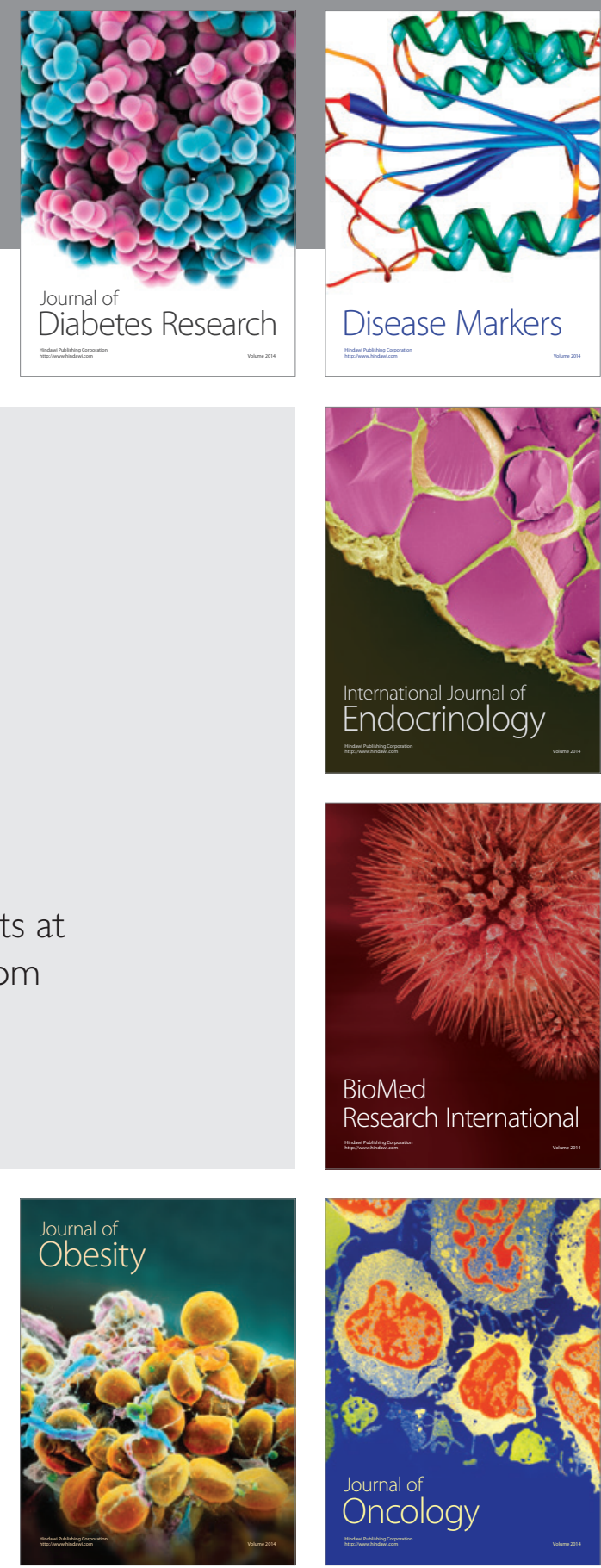

Disease Markers
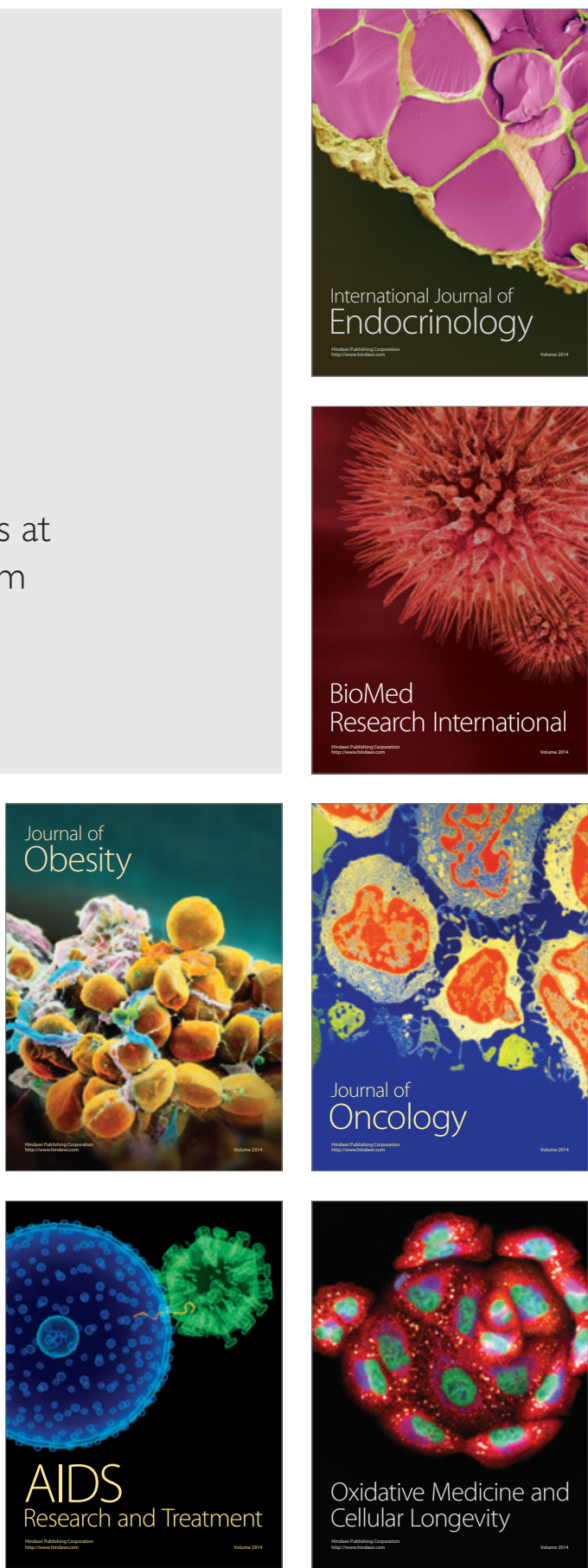